\title{
Les légendes relatives à l'origine hybride et à la naissance des girafes selon les auteurs arabes
}

Legends relating to the hybrid origin and birth of giraffes according to Arab authors

$$
\text { الأساطير المتعلقة بأصل الزرافة الهجين وولادتها حسب المؤلفين العرب }
$$

\section{Thierry Buquet}

\section{OpenEdition}

\section{Journals}

\section{Édition électronique}

URL : http://journals.openedition.org/beo/1320

DOI : 10.4000/beo.1320

ISSN : 2077-4079

\section{Éditeur}

Presses de l'Institut français du Proche-Orient

\section{Édition imprimée}

Date de publication : 30 avril 2014

Pagination : 125-147

ISBN : 978-2-35159-403-2

ISSN : 0253-1623

\section{Référence électronique}

Thierry Buquet, « Les légendes relatives à l'origine hybride et à la naissance des girafes selon les auteurs arabes », Bulletin d'études orientales [En ligne], LXII | 2014, mis en ligne le 04 juin 2014, consulté le 19 avril 2019. URL : http://journals.openedition.org/beo/1320 ; DOI : 10.4000/beo.1320 


\section{Les légendes relatives à l'origine hybride et à la naissance des girafes selon les auteurs arabes}

Thierry BUQUET

Institut français du Proche-Orient

Si l'histoire de la girafe dans l'Antiquité égyptienne ${ }^{1}$, gréco-latine ${ }^{2}$ puis au Moyen Âge ${ }^{3}$ est aujourd'hui mieux connue, son histoire en terre d'islam a été relativement peu étudiée ${ }^{4}$. Un article récent de Remke Kruk en donne une bonne synthèse, non exhaustive ${ }^{5}$. La présente étude se propose de développer et de préciser certains points qui y sont abordés, notamment à propos de l'origine des girafes : leur hybridité supposée, les légendes autour de leur naissance et la licéité de la consommation de leur viande selon l'islam. L'article de R. Kruk aborde bien d'autres aspects de l'histoire de cet animal, notamment son statut de cadeau diplomatique et de vedette des ménageries princières ${ }^{6}$ que nous n'évoquerons ici que dans le cadre de la connaissance directe de cet animal par les savants arabes.

La brève notice consacrée à la girafe dans l'Encyclopédie de l'islam ${ }^{7}$, rédigée par le spécialiste de la chasse et de la fauconnerie François Viré ${ }^{8}$, donne une fausse image de la connaissance de cet animal en terre d'islam. L'auteur y affirme notamment que «les Arabes n'ont guère connu la girafe et ne s'y sont pas intéressés », et que ni al-Damīrī ni al-Qazwīnī ne la mentionnent, ce qui est également inexact. F. Viré évoque comme seule source arabe al-Ǧāhiz, qui critique, dans son Kitāb al-Hayawān" ${ }^{9}$, ses prétendues origines hybrides. Al-Ǧāhiz détaille l'explication qu'on a voulu donner à l'origine des girafes, selon lui nommées en persan uštur-gāw-palank, «chameau-vache-hyène ». Pour justifier ce nom composite, certains prétendent, selon al-Ǧāhiz, que la girafe serait un hybride

\footnotetext{
CANNUYER 2010.

GATIER 1996 ; GATIER 2005 ; BUQUET 2006.

BUQUET 2008 ; BUQUET 2012b.

EISENSTEIN 1992 ; MEINECKE-BERG 2000 ; SUBLET 2005.

KRUK 2008.

6 Étienne Quatremère donne de nombreux exemples de ces cadeaux diplomatiques de girafe, dans son édition de l'Histoire des sultans mamelouks d'al-Maqrīzī (Paris, 1837), note 128 p. 106-108 et addenda p. 273.

7 VIRÉ 2005.

8 F. Viré est par ailleurs auteur de nombreuses et très précieuses notices zoologiques dans l'Encyclopédie de l'islam.

9 Al-Ǧāhịiz, Kitāb al-ḥayawān, éd. HĀRŪN, I, 38, p. 241-243 ; Le cadi et la mouche, trad. SoUAMI, p. 207-209.
} 
obtenu au bout de deux générations, d'une chamelle, d'une hyène mâle et d'une vache sauvage (ou un oryx). L'hyène mâle couvre une chamelle, et le fruit de leur union, si c'est un mâle, couvrant une vache sauvage, donnera la girafe. Mais pour al-Ǧāhìz, la girafe n'est pas un hybride, et il explique que ces unions contre-nature successives sont le fruit des imaginations débordantes d'auteurs peu scrupuleux qui cherchent à expliquer l'origine des animaux par l'étymologie de leurs noms. En persan, le nom de l'autruche, qui est appelée oiseau-chameau ashtarmurgh (aštar: chameau et murǵ : oiseau), comme chez les Grecs (struthiokamelos, struthio : oiseau, kamelos : chameau, dromadaire) ${ }^{10}$, subit le même phénomène d'hybridation linguistique.

\section{L'hybridité de la girafe dans l'Antiquité}

Selon F. Viré, l'hybridité de la girafe aurait été acceptée par la majorité des auteurs antiques, qui la considéraient comme le produit du croisement entre des camélidés, des bovins et des panthères. Pourtant, la plupart des auteurs classiques et médiévaux n'indiquent pas qu'il s'agit d'un animal hybride, mais appuient leurs descriptions sur le nom de l'animal ${ }^{11}$, en comparant la girafe avec le chameau et la panthère pour ses principaux aspects et avec d'autres animaux pour son comportement ou certaines parties de son anatomie. En effet, le nom donné à la girafe par les Grecs, dès l'époque ptolémaïque, est kamelopardalis, repris ensuite en latin en camelopardalis, ce qui signifie littéralement " chameau-panthère ». Les descriptions antiques de la girafe semblent alors vouloir parfois justifier le nom de l'animal à partir de son apparence physique : apparaissent toujours des éléments évoquant le chameau (son cou, sa démarche) ou la panthère (son pelage tacheté ou bigarré). La majorité des auteurs grecs et latins savent qu'il s'agit d'un animal réel et d'une espèce propre, et non d'une création chimérique issue d'une hybridation. Le géographe Strabon (mort en 19 après J.-C.) insiste notamment sur les différences entre l'animal réel et son nom: il critique la ressemblance supposée avec la panthère à cause du caractère pacifique de la girafe, qui a la douceur d'un animal domestiqué, et par son apparence physique, ne ressemblant en rien à la panthère ; Strabon précise que les taches de son pelage se rapprochent plus de celles d'un cervidé que d'un félin. Il pointe aussi les différences avec le chameau en précisant que son cou est beaucoup plus grand, jusqu'à manger sur le sommet des arbres ${ }^{12}$. Le nom composé de l'animal est donc une convention et n'a pas de signification zoologique réelle ${ }^{13}$.

Seulement trois auteurs grecs présentent la girafe comme un hybride issu de l'accouplement d'espèces distinctes ${ }^{14}$ : Poséidonios d'Apamée ( $\mathrm{II}^{\mathrm{e}}-\mathrm{I}^{\mathrm{er}} \mathrm{s}$. av. J.-C.), transmis

\footnotetext{
10 VIRÉ 1993 a.

11 GATIER 1996, p. 910.

12 Strabon, Géographie, éd. JONES, 17.3, 4-5, p. 336-337.

13 BODSON 2005, p. 471-472.

14 GATIER 1996, p. 910.
} 
par Diodore de Sicile ( $\mathrm{I}^{\mathrm{er}} \mathrm{S}$. av. J.-C.) ${ }^{15}$, Oppien d'Apamée dans ses Cynégétiques (III ${ }^{\mathrm{e}} \mathrm{s}$. apr. J.-C., ${ }^{16}$ et Timothée de Gaza ( $\mathrm{V}^{\mathrm{e}}-\mathrm{VI}^{\mathrm{e}}$ s. ap. J.-C.) ${ }^{17}$.

Diodore signale la présence en Afrique d'animaux à double nature, dont l'autruche. Ensuite, il passe à la girafe. Dans le passage suivant, il cite le tragelaphos (« chèvre-cerf ») et la bubalis comme des « espèces à double forme ». La girafe de Diodore est décrite comme le mélange des deux animaux présents dans sa désignation, et compare ses caractéristiques physiques avec celles du chameau et de la panthère. Oppien parle lui aussi d'une nature mixte ${ }^{18}$, mais va plus loin en précisant que la panthère s'est unie avec le chameau pour la produire. Chez Oppien, l'autruche suit la girafe et est décrite également comme une merveille à double nature, mélange d'oiseau et de chameau, même s'il n'évoque pas une possible origine hybride de l'autruche.

Le texte de Timothée de Gaza est beaucoup plus difficile à établir car il nous est parvenu sous forme de fragments médiévaux incomplets ${ }^{19}$. Des extraits de son traité sur les animaux, le Peri zôôn, ont été inclus dans une encyclopédie zoologique du IX siècle, la Syllogé Constantini, écrite à la cour de l'empereur byzantin Constantin VII ${ }^{20}$. Il existe également un résumé (épitomé) byzantin du $\mathrm{XI}^{\mathrm{e}}$ siècle ${ }^{21}$. Enfin, des passages du Peri zôôn sont cités par alMarwazī au XII ${ }^{\mathrm{e}}$ siècle ${ }^{22}$. Dans la Syllogé Constantini, la girafe est présentée comme une sorte de mélange entre deux animaux, le chameau et la panthère, réunis en un seul. L'épitomé du XI ${ }^{\mathrm{e}}$ siècle dit plus clairement que la girafe est née de l'union (grec épimixia, " relation mutuelle, commerce », sens moderne : "métissage ») de deux animaux ${ }^{23}$. Al-Marwazī ne reprendra pas ces passages sur la prétendue hybridité, et ce tout à fait volontairement, comme nous le verrons plus loin.

Quoiqu'il en fût des intentions réelles d'Oppien et Timothée, entre « mélange » figuré et «hybridation" réelle, la kamelopardalis est présentée dans leurs textes comme une merveille de la nature. La transformation, à l'époque impériale, de la girafe, animal bien connu et décrit à l'époque hellénistique, et vu notamment à plusieurs reprises à Rome entre le $\mathrm{I}^{\mathrm{er}}$ et le $\mathrm{III}^{\mathrm{e}}$ siècle ${ }^{24}$, en une merveille « hybride », n'a rien d'étonnant : on connaît le goût pour les prodiges à Rome et dans le reste de l'Empire. Les monstres de la mythologie et les hybrides «linguistiques » sont devenus des réalités admises par la majorité des

15 Diodore de Sicile, Bibliothèque historique, éd. CASEVITZ, p. 176.

16 Oppien, Cynégétiques, éd. MAIR, III, 461-482, p. 152-153.

17 Timothée de Gaza, Peri zôôn, trad. BodenHEIMER, chap. 24, p. 31.

18 Une scholie médiévale dans un manuscrit d'Oppien commente ce passage, à propos du mot « mixta» : « Girafe : un monstre naturel et en même temps une merveille, unifiant d'une certaine manière deux espèces en une. » (Scholia et Paraphrases in Nicandrum et Oppianum, p. 266, $\mathrm{n}^{\circ} 462$ ).

19 ZUMBO 1996 ; MinNiTI COLONNA 1977 ; WELLMANN 1927.

20 Supplementum Aristotelicum, éd. LAMBRos 1885.

21 Excerpta (sic) ex Timothei Gazaei libris de animalibus, éd. HAUPT, 1869 ; Peri zôôn (On animals), trad. angl. RABINOWITZ et BODENHEIMER, 1949.

22 KRUK 2001.

23 BUQUET $2012 \mathrm{a}$, § 44.

24 GATIER 1996. 
auteurs. L'étrange, le merveilleux, l'inhabituel, l'hybride et l'exotique trouvent souvent une explication elle-même «merveilleuse » ${ }^{25}$. Par exemple, Pline l'Ancien parle d'un félin hybride, né de l'adultère d'une lionne et d'un mâle panthère ${ }^{26}$. L'animal n'est pas nommé, mais à la suite de Pline, le leopardus (grec leopardos), dont le nom apparait aux II et III siècles, sera très souvent présenté comme le fruit de ces amours adultérines ${ }^{27}$.

La kamelopardalis va être également diffusée au Proche-Orient antique sous forme figurée. De nombreuses mosaïques, aujourd'hui conservées en Palestine, Jordanie ou Syrie, représentent, parmi une faune exotique très variée, des girafes. Elles sont figurées tantôt de façon naturaliste, tantôt sous la forme d'un chameau tacheté, comme par exemple sur une mosaïque à Pétra (figure 1). Il semble dans ce cas que les artistes, aient alors synthétisé dans le chameau tacheté les deux parties d'un nom d'un animal mal connu, faute de modèle vivant ou pictural ${ }^{28}$.

\section{Quelle influence des sources antiques à propos de l'hybridité de la girafe?}

Oppien d'Apamée et Timothée de Gaza nous intéressent ici tout particulièrement car leurs œuvres ont été connues dans le monde arabe. Sans qu'Oppien ne soit nommément cité, des extraits de ses écrits peuvent être reconnus dans certains traités cynégétiques arabes, comme le Kitāb al-mașāyid wa-l-mațārid (Traité de chasse avec des animaux et des oiseaux de proie) de Kušāğim (m. avant 971) ${ }^{29}$ et dans le livre de chasse d'al-Mansūr (XIII s.) ${ }^{30}$. Oppien est également repérable dans le Țaba 'i’ al-Hayāwan d'al-Marwazī (XII ${ }^{\mathrm{e}} \mathrm{s}$.) ${ }^{31}$ ou encore chez al-Qalqašandīi ${ }^{32}$. Dans ces textes, il est fait mention de deux variétés de panthères (al-namir), l'une corpulente avec une queue courte, l'autre moins forte avec une longue queue. Cette évocation de deux races de panthères (grec pardalis) n'existe que chez deux auteurs antiques : Oppien ${ }^{33}$ et Timothée de Gaza ${ }^{34}$. Timothée est avant tout un compilateur et il a notamment beaucoup emprunté à Oppien ${ }^{35}$ : il est probable qu'il lui ait repris ce passage sur les panthères.

25

LI CAUSI 2008, p. 113 et suiv.

Pline l'Ancien, Histoire naturelle, VIII, 17, éd. ERNOUT, p. 42-43.

BUQUET 2011, p. 20-21.

GATIER 1996 et 2005.

Kušāōim, Kitāb al-mașāyid wa-l-mațārid, éd. TALAS, 1954, p. 211-212.

Al-Manșūr, On Hunting, éd. CLARK \& DERHALLI, 2001, p. 76.

KRUK 2001, p. 369.

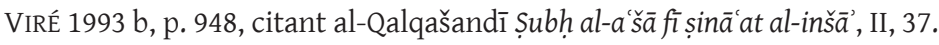

Oppien, Cynégétiques, trad. L'Allier, 2009, III, 63, p. 95.

Timothée de Gaza, Peri zôôn, § 11, p. 25.

Plusieurs emprunts à Oppien sont signalés par les éditeurs du traité cynégétique d'al-Manșūr (p. 8), à propos du croisement entre le renard et la chienne produisant un lévrier, et de l'ichneumon, capable de tuer un crocodile. Ces anecdotes sont également reprises par Timothée (Peri zôôn, § 5, p. 21 et § 42, p. 42-43). 
Timothée de Gaza a souvent été évoqué comme une source importante de la zoologie arabe ${ }^{36}$. Le Peri Zôôn a été traduit en syriaque et en arabe, dont le texte est connu sous le titre Kitāb al-hayawān al-qadìm ${ }^{37}$, probablement écrit au VIII ${ }^{e}$ ou au $\mathrm{IX}^{\mathrm{e}}$ siècle, mais qui ne nous a pas été directement transmis ${ }^{38}$. La présence de citations de son œuvre a été conjecturée, par exemple, mais de façon peu certaine, chez Ibn Qutayba ${ }^{39}$ ou chez al-Tawhīdī ${ }^{40}$. Le Nu ūut al-hayawān, compilation zoologique d'inspiration aristotélicienne, datant du $\mathrm{x}^{\mathrm{e}}$ siècle, contient 14 notices d'animaux dont les textes correspondent à ceux de Timothée ${ }^{41}$.

Timothée n'est cité nommément à notre connaissance qu'à deux reprises par des auteurs arabes, chez al-Marwazī, sous les noms de Țīmūtiyūs, Țīmūsūs, Ațmūniyūs et Ațmīnūs ${ }^{42}$, et chez al-Qazwīnī sous le nom de Ṭihmān (parfois retranscrit Ṭimāt dans certaines éditions) ${ }^{43}$. Al-Marwazī cite explicitement Timothée à propos du lion, du cheval, de la chèvre sauvage, du rhinocéros, du catoblepas, de l'hyène, de l'écureuil, des serpents et de la girafe. Al-Qazwīnī le cite lui aussi à propos de la girafe : il évoque son origine hybride (en reprenant l'histoire rapportée par al-Ğahiz) et ajoute ensuite que "Ṭihmān le Sage » rapporte que, près de l'équateur, toutes sortes d'animaux se rendent en été près des points d'eau pour se désaltérer. Parfois, certains s'accouplent avec d'autres espèces, générant des animaux comme la girafe ou d'autres hybrides comme le sim (croisement d'hyène mâle et de louve) ou le 'isbār (croisement du loup et de l'hyène femelle). ${ }^{44}$

Ces rencontres aux abords des points d'eau ne sont pas évoquées ni dans l'excerptum, ni dans l'épitomé grecs de Timothée de Gaza ${ }^{45}$. Al-Marwazī fait mention, lorsqu'il cite Timothée, de la réunion de girafes aux abords des points d'eaux dans les régions désertiques de l'« Inde », mais sans dire que les girafes y rencontrent d'autres animaux et encore moins qu'elles s'y accouplent avec d'autres espèces ${ }^{46}$. Cette histoire d'hybridations aux abords de point d'eaux se trouve déjà chez Aristote ${ }^{47}$ et chez Pline ${ }^{48}$. Cette information est reprise par plusieurs auteurs arabes, par exemple Ibn Qutayba ${ }^{49}$ et Ibn Hुallikān ${ }^{50}$, qui donnent une

36 ULLMANN 1972, p. 15-17 et 23.

37 CONTADINI 2003, p. 20.

38 LAUZI 2012, p. 48-49; WELLMANN 1927, p. 181.

39 Ibn Qutayba, The natural history section from a $9^{\text {th }}$ century Book of Useful Knowledge. The 'Uyūn al-Ahbār of Ibn Qutayba, éd. BODENHEIMER et KOPF, 1972.

40 Al-Tawhīì̄ī, The Zoological Chapter of the Kitāb al-Imtā' wal-Mu'ānasa, éd. KoPf, 1956.

41 KRUK 2007, p. 57. Manuscrit de Saint-Petersbourg, Musée Asiatique, 649d.

42 KRUK 2001, p. 358.

43 'A $\check{g} \bar{a}$ ’ib al-mahlūqāt, passage traduit par KRUK 2008, p. 583-584.

44 KRUK 2008, p. 584.

45 Ceci pourrait faire douter de l'identification du « Tihman » d'al-Qazwīnī à Timothée de Gaza.

46 KRUK 2001, p. 364.

47 Aristote, Génération des animaux, 746b, éd. LouIs, p. 87-88; Histoire des animaux, 606b 19, éd. LoUIS, p. 59-60.

48 Pline, Histoire naturelle, éd. ERNOUT, VIII, 17, 42.

49 Ibn Qutayba, «The Natural History Section from a 9th Century Book of Useful Knowledge, The 'Uyūn al-Ahbār of Ibn Qutayba », éd. KoPF et BODENHEIMER, p. 43.

50 Cité par al-Damīrī, trad. JAYAKAR, II, p. 8. 
origine abyssine à la girafe à cause de son statut d'hybride supposé, créé au bord des points d'eau dans les régions désertiques, se situant en Abyssinie. Ces rencontres sont également évoquées dans le $N u$ 'ùt al-hayawān ${ }^{51}$, où elles servent également d'explication à l'origine hybride de la girafe. Le texte explique que cet animal est composé miraculeusement de deux substances, dont celle de la panthère. Les hybridations aux abords des points d'eaux seraient à l'origine d'animaux étranges comme la girafe ${ }^{52}$. Ce texte cite à tort comme source Aristote (nommé ici « Le Philosophe ») alors que celui-ci n'évoque jamais la girafe dans son œuvre zoologique. La source pourrait être ici un passage perdu de Timothée de Gaza, car Oppien, s'il dit que la girafe est de nature mixte, générée par la panthère et le chameau, n'en donne aucune explication et ne reprend pas l'histoire des rencontres près des points d'eau ${ }^{53}$.

Aristote est également évoqué à propos de la girafe par al-Mas'ūdīi ${ }^{54}$, qui dit « qu'une longue notice sur la girafe se trouve dans le grand ouvrage d'Aristote sur les animaux; cet auteur y explique les fonctions de chaque organe de la girafe et chez tous les animaux en général. Nous avons exposé ${ }^{55}$ dans notre ouvrage intitulé Questions et expériences ${ }^{56}$ tout ce qu'il est nécessaire de connaître sur le sujet ». Il est fort probable qu'al-Mas'ūdī cite un traité pseudo-aristotélicien, comme le Nu'ūt al-hayawān, texte contemporain du siècle

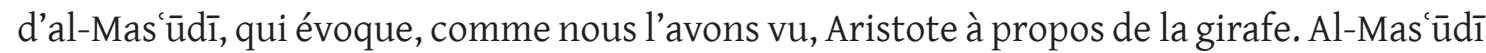
a sans doute eu accès au Nu'ūt ou à sa source et non pas à Aristote, comme l'exemple de la girafe le montre bien ${ }^{57}$. Al-Mas '̄ùd mentionne également les accouplements hybrides aux abords des points d'eaux, mais en citant al-Ǧāhì ${ }^{58}$.

Les auteurs arabes ont également eu accès à la traduction de la zoologie d'Aristote par Yahyā b. al-Bițīq (IX siècle). Cet auteur a traduit notamment l'Histoire des animaux et la Génération des animaux où figurent les passages sur les rencontres aux abords des points d'eaux, provoquant la naissance d'animaux hybrides ${ }^{59}$. Mais l'influence la plus probable demeure celle de sources pseudo-aristotéliciennes : il n'y a en effet que peu de correspondances directes entre le texte du Nu'üt al-hayawān et ceux d'Aristote dans leur traduction arabe ${ }^{60}$.

Al-Qazwīnī attribue directement, comme nous l'avons déjà mentionné, l'explication de l'origine hybride de la girafe à Timothée de Gaza. Il évoque également d'autres hybridations

51 Tunis, BN, Ms. 16385, f. 16v-17, cité par KRUK 2007, p. 58-59.

52 KRUK 2007, p. 58.

53 Oppien, Cynegetica, éd. MAIR, p. 152-153.

54 Al-Mas'ūdī, Les prairies d'or, trad. PELLAT, § 846, p. 322.

55 La traduction de Barbier de Meynard et de Pavet de Courteille (1864, t. III, p. 5) donne « Nous lui avons emprunté... », ce qui semble plus logique dans le contexte de compilation d'Aristote. Le verbe arabe ata peut signifier « suivre » ou « venir de ». Une traduction alternative donnerait : « Nous l'avons suivi... ».

56 Cette œuvre est hélas perdue.

57 Aristote, Generation of animals. The Arabic translation commonly ascribed to Yahya ibn al-Bitriq, introduction, p. 42.

58 Al-Mas'ūdī, Prairies d'or, chap. 3, § 845, trad. PELlat, t. II, p. 322.

59 Generation of animals. The Arabic translation..., 746 b, p. 89-90.

60 CONTADINI 2003, p. 20. 
à propos de certaines espèces, qui sont également décrites comme telles par Timothée : le mulet, le sim', le 'isbār, le daysam (loup-chien), le sulāqìya (slougi, sorte de lévrier, supposé être le produit de l'union du loup et de l'hyène femelle) ${ }^{61}$. Pour l'hybridation à la deuxième génération de la girafe, al-Qazwīnī semble dépendant de ses prédécesseurs arabes, notamment al-Ǧāhiz, tant la description de l'origine multiple de la girafe ressemble à la sienne. Al-Qazwīnī n'attribue pas cette légende à Timothée, mais seulement l'explication des rencontres aux abords des points d'eau, en le citant cette fois nommément, comme s'il cherchait à expliquer et à justifier cette génération rocambolesque par l'autorité d'un savant antique (Tihmān al-ḥakìm, le sage, le savant) ${ }^{62}$.

Il est difficile d'affirmer que les autres éléments de la description de la girafe par Timothée de Gaza, notamment son anatomie, ont été repris par les auteurs arabes. Les descriptions zoologiques antiques d'animaux rares ou exotiques procèdent souvent par comparaison avec des animaux mieux connus : ici, pour la girafe sont évoqués le bœuf, le chameau, la gazelle, le cerf pour certaines parties (pattes, tête, cornes, queue, etc.) ou la panthère pour les couleurs de son pelage. On retrouve ce type de comparaisons dans la littérature médiévale, tant en Occident qu'en terre d'islam. Par exemple, Oppien et Timothée comparent la queue de la girafe avec celle de la gazelle; Timothée ajoute qu'elle est de couleur noire à son extrémité ${ }^{63}$. La plupart des auteurs arabes décrivent aussi la queue de la girafe comme ressemblant à celle de la gazelle (par exemple al-Ǧāhiz, Nu ūit al-Hayawān, al-Qazwīnī, al-Damīīī) ; seul al-Marwazī, qui cite Timothée, reprend la description de l'extrémité de couleur noire. Il est impossible, sur un détail aussi simple que la comparaison de la queue, de conclure à l'utilisation systématique de la description de Timothée par les auteurs arabes ; les autres parties descriptives relatives au bœuf, au cerf ou au chameau, très génériques, ne sauraient constituer des preuves formelles d'emprunt direct.

Chez Timothée se trouve unélément original : la description de la démarche particulière de la girafe qui va l'amble, c'est-à-dire qu'elle lance en même temps les deux jambes d'un même côté, puis ensuite les deux autres. Cette caractéristique n'a été soulignée que par deux auteurs antiques : Héliodore (IV ${ }^{\mathrm{e}} \mathrm{s}$. apr. J-C.) ${ }^{64}$ et Timothée ${ }^{65}$. Ce dernier souligne que cette démarche est en contradiction avec celle généralement utilisée par les quadrupèdes qui « lancent à tour de rôle de chaque côté le pied, du côté droit le pied avant, puis à gauche celui de derrière », telle que l'a décrite Aristote ${ }^{66}$. Al-Marwazī reprend la description de la

61 EISENSTEIN 1992, p. 82.

62 Al-Marwazī qualifie également Timothée avec cette épithète : Tịmūsūs, Ațmūniyūs al-ḥakim (KRUK 2007, p. 363364).

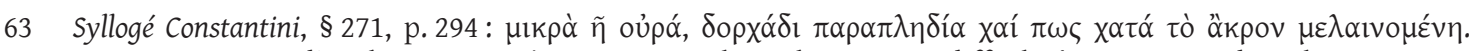
Ce texte permet d'expliquer ce même passage chez al-Marwazī, difficile à transcrire dans le manuscrit (KRUK 2008, p. 575, note 25).

64 Héliodore, Éthiopiques, 10, 27-28, trad. MAILLON, t. III, p. 108-109.

65 Syllogé Constantini, § 271, p. 294.

66 De incessu animalium, 712 a 25. Sur les problèmes philologiques posés par ce passage, voir MORGAN 1988. 
démarche en la condensant: selon lui, elles lancent leur patte avant droite, puis ensuite l'avant gauche et l'arrière gauche, sans faire mention d'une simultanéité. D'autres auteurs arabes, sans citer Timothée, évoquent cette démarche particulière et cette question de l'ordre du mouvement des pattes : al-Ǧāhị ${ }^{67}$, al-Dimašqī ${ }^{68}$ et al-Damīrī ${ }^{69}$ disent qu'elle avance le pied droit de devant et le pied gauche de derrière, au contraire des autres quadrupèdes. La remarque est zoologiquement fausse mais pourrait s'expliquer par une mauvaise compréhension du texte de Timothée de Gaza: nous avons vu qu'al-Marwazī lui-même interprète à sa manière le passage sur l'amble, alors qu'il cite explicitement Timothée. Al-Ǧāhiz et ses compilateurs, comme Šams al-Dīn al-Dimašqī et al-Damīrī, semblent dépendre d'une source indirecte citant Timothée, ce qui pourrait induire une transformation du passage sur l'amble et sa mauvaise compréhension.

En conclusion, Oppien et Timothée sont les deux seuls auteurs à dire que la girafe est hybride ou formée d'une sorte de mélange; l'œuvre de ces deux auteurs a été transmise aux auteurs arabes : cela a influencé la perception « hybride » de la girafe à laquelle s'est joint le nom persan de l'animal, lui aussi une sorte de composé. Ce zoonyme persan auraitil lui-même été influencé par les textes grecs ? On peut légitimement se poser la question car l'autruche est aussi par son nom une composition, un mélange de chameau et d'oiseau « uštur-murg » en persan, mélange que l'on retrouve en grec ancien.

L'influence de la notice de Timothée de Gaza sur les auteurs arabes, ne peut être totalement démontrée - sauf pour al-Marwazī et en partie pour al-Qazwīn̄̄-, faute d'avoir à notre disposition un témoin intermédiaire de son œuvre en terre d'islam (traduction arabe perdue, ou compilation pseudo-aristotélicienne citant nommément Timothée). Néanmoins, plusieurs aspects originaux du texte de Timothée, repris par les auteurs arabes, laissent présumer de son utilisation directe ou indirecte (par exemple à travers le $N u$ 'uut al-hayawān, directement influencé par Timothée) : l'histoire des rencontres entre espèces différentes aux abords des points d'eau (passage perdu de Timothée qui lui est attribué par certains auteurs arabes) et, surtout, la description de la marche à l'amble. Ainsi, nous pouvons affirmer que les légendes arabes autour de l'hybridité de la girafe trouvent très probablement leur source chez Timothée de Gaza.

\section{Une hybridité dénoncée}

Al-Ǧāhị, dans le Kitāb al-Tarbǐ wa-l-tadwīr, où il propose à un personnage fictif de « lui poser sur le mode ironique cent questions destinées a révéler au monde l'étendue de son ignorance ${ }^{70}$, utilise l'exemple de l'hybridité de la girafe comme une de ces questions supposées embarrasser la fausse science : «Renseigne-moi sur la girafe : est-elle le produit

67 Al-Ǧāhịiz, Kitāb al-ḥayawān, VII, p. 243.

68 Al-Dimašqī Šams al-Dīn, Manuel de la cosmographie, trad. MEHREN, p. 216.

69 Al-Damīīī, Hayāt al-hayawān, trad. JAYAKAR, II, p. 8.

70 ADAD 1966, p. 269 et 275. 
d'une hybridation entre chamelle et hyène mâle ? ${ }^{71}$. Comme si cette question avait, parmi d'autres, valeur d'exemple pour mettre en scène l'ignorance habituelle de son temps, telle une « idée reçue » à combattre.

Selon al-Ğāhiz, certains veulent expliquer le nom de l'animal en persan, composé de trois éléments, pour aboutir à une hybridation impliquant trois espèces animales, en deux générations successives :

« Appeler la girafe du nom persan uštarkawbalank aboutit à en faire le produit hybride d'une chamelle sauvage, d'une vache sauvage (oryx) et de l'hyène mâle, dans la mesure où les Persans nomment les choses par procédé de dérivation (ištiqāqāt) ; c'est ainsi qu'ils appellent l'autruche (na'äma) aštarmurgh, comme pour sous entendre que cet animal est un oiseau (țāir) et un chameau (ğamal) à la fois, mais cela ne nous oblige pas à déduire que cet animal est le produit d'un croisement entre oiseau et chameau et à conclure que l'autruche, comme la girafe, est un produit hybride. Mais nos gens se fondant sur la similitude (šabah) entre deux animaux voisins (mutaqārib), les ont nommés en partant du nom de ces deux espèces. ${ }^{72}$

Selon al-Ǧāhiz, cette double hybridation n'existe uniquement que pour «justifier » l'existence de zoonymes formés de plusieurs noms d'espèces, sur la base de la ressemblance entre celles-ci et l'animal ainsi nommé.

Al-Ǧăhiz utilise l'argument que deux animaux créant un hybride doivent avoir la même taille, selon les explications d'Aristote : «l'union est féconde quand la durée de la gestation est la même et que la taille des animaux n'est pas trop différente » ${ }^{73}$. Al-Ǧāhị ne reprend pas l'argument de la durée de gestation, mais donne celui de la taille de la matrice pour porter le petit d'un animal plus grand. Ainsi il semble impossible que l'hyène mâle puisse monter une chamelle ou qu'une panthère femelle puisse porter en elle le petit d'un chameau ${ }^{74}$. Une autre critique a été portée par Ibn al-Faqīh : bien qu'il répète dans sa description de la girafe les histoires sur sa génération hybride, il conclut pourtant que c'est une erreur, et que cet animal ne peut avoir été engendré par plusieurs mâles, car le chameau ne couvre pas la vache ${ }^{75}$.

Al-Marwazī ne reprend pas l'idée de l'origine hybride qui est chez Timothée, sa compilation est sélective et il ne conserve que ce qui s'accorde à sa pensée. En effet, al-Marwazī a vu à Ispahan en 1081-1082 une girafe offerte au sultan Malik Šāh, qu'il a attentivement observée à la demande du vizir Nizām al-Mulk. Il se sert de cette observation pour affirmer qu'elle ne peut être l'hybride d'un chameau et d'une panthère, comme l'affirment certains ${ }^{76}$. L'observation a également fourni des arguments à al-Nuwayrī, témoin d'une naissance de girafe en captivité, qui se sert de cette génération « naturelle »

71 Al-Ǧāḥīz, Kitāb al-Tarbî̀ wa-l-tadwìr, trad. ADAD, § 49, p. 39-40.

72 Al-Ǧāḥīz, Kitāb al-hayawān, trad. SoUAMI, p. 209.

73 Aristote, Histoire des animaux, 606 b 19, éd. Louis, p. 59.

74 Al-Ǧāḥ̣̄̄, Kitāb al-ḥayawān, VII, 241-243.

75 Ibn al-Faqīh, Abrégé du livre des pays, trad. MASSÉ, p. 94.

76 EISENSTEIN 1992, p. 131 ; ISKANDAR 1981, p. 272 ; KRUK 2008, p. 577. 
pour confirmer les dires d'al-Ǧāhị s'opposant à l'hybridité de la girafe ${ }^{77}$. D'autres auteurs ont affirmé que la girafe pouvait procréer par elle-même : al-Wațāt (m.1318) parle d'un " fait qui a été observé » ${ }^{78}$. Al-Damīrī précise que la girafe est une espèce propre, au même titre que le cheval ou l'âne, que cela a été prouvé par le fait qu'elle donne naissance à ses petits, et que cela a été observé de façon certaine ${ }^{79}$. Un tel événement s'est effectivement produit au Caire, en 1271, dans le Château de la Montagne (Qal'at al-ğabal) : selon al-Maqrīzī, une girafe donna naissance à un petit girafon qui fut nourri par une vache. Cette naissance est confirmée par plusieurs sources ${ }^{80}$. Al-Nuwayrī affirme qu'il a été lui-même le témoin d'une telle naissance au Caire, et que le girafon vivait toujours à l'époque où il écrit ${ }^{81}$. Né en 1279, il ne peut avoir été témoin de la naissance du Château de la Montagne en 1271 : ceci laisse supposer que ces naissances en captivité ne devaient pas être rares.

Ces girafes étaient gardées dans les ménageries du sultan et de nombreux témoignages confirment leur présence en captivité au Caire et dans d'autres grandes cités arabes ou perses ${ }^{82}$. La plus ancienne mention concerne la ménagerie du prince tulunide Humarāway, à la fin du IX siècle, qui consistait en un vaste ensemble d'écuries, d'étables et d'enclos divers réservés pour chaque espèce captive. Al-Maqrīzī, qui nous a transmis la description de cette ménagerie, nous dit qu'un espace spécifique y était réservé aux girafes ${ }^{83}$. Outre les sources arabes, il faut mentionner les nombreuses descriptions des voyageurs occidentaux, qui lors de leur visite du Caire, ne manquent pas de décrire les girafes ${ }^{84}$. Citons, à titre d'exemple, parmi la trentaine de témoignages que nous avons repérés, du XIV au XVI siècle (inventaire sans doute non exhaustif), Giorgio Gucci, en $1384^{85}$, et Ogier d'Anglure, en $1395^{86}$, qui décrivent des enclos comprenant jusqu'à huit girafes, mâles, femelles et girafons compris. Les petits ne naissaient d'ailleurs pas toujours en captivité, car il était d'usage de les capturer en bas âge dans leur milieu naturel, selon le témoignage de Léon l'Africain ${ }^{87}$, pour les domestiquer plus facilement. Al-Mas' ${ }^{\mathrm{u}} \mathrm{d} \mathbf{i}$ dit d'ailleurs qu'il existe

\footnotetext{
77 Al-Nuwayrī, Nihāyat al-'arab fífunūn al-adab, vol. 9, p. 317-318, cité par MUHANNA 2012, p. 174, note 311.

78 Al-Wațwaț, Manāhiğ al-fikar wa-mabāhiğ al-'ibar, éd. SZEGIN, p. 82-83, cité par KRUK 2008, p. 587.

79 Al-Damīīi, Hayāt al-hayawān, trad. JAYAKAR, II, p. 8.

80 Al-Maqrizī, Histoire des sultans mamelouks, éd. QUATREMÈRE, t. II, p. 106. En note 128, Quatremère mentionne les témoignages d'Abū al-mahāsin (Histoire d'Égypte), de Ḥasan ibn Ibrāḥ̄m et d'al-Suyūṭ̂̄.

81 Al-Nuwayrī, Nihāyat al-'arab fï funūn al-adab, vol. 9, p. 317-318, cité par MUHANNA 2012, p. 174, note 311.

82 Al-Maqrizī, Histoire des sultans mamelouks, éd. QUATREMÈRE, t. II, p. 106, note 128, où Quatremère cite de nombreuses sources relatives à la présence et l'exhibition de girafes en terre d'islam.

83 Al-Maqrīzī, Description historique et topographique de l'Égypte, éd. CASANOVA, p. 221.

84 BUQUET 2013.

85 Viaggi in Terra Santa, di Lionardo Frescobaldie d'altri del secolo XIV, éd. GARGIOLLI, p. 297-299.

86 Le saint voyage de Jherusalem du seigneur d'Anglure, éd. BOGHARDON et LOGNON, p. 62.

87 Léon l'Africain, Description de l'Afrique, trad. TEMPORAL, II, p. 281.
} 
selon lui deux types de girafes, celles qui sont sauvages et les autres, domestiquées, comme chez les éléphants ${ }^{88}$.

\section{Une autre légende sur la naissance des girafes}

La girafe a souvent été louée en terre d'islam pour la douceur de son caractère ${ }^{89}$. Mais une légende relayée par les auteurs arabes et persans vient contredire cette observation. Ibn Bahtī̄̌sū' (XI siècle), dans son traité Manāfic al-ḥayawān (Utilité des animaux) ${ }^{90}$, nous livre l'histoire suivante, conservée dans un manuscrit daté de la fin du XIII ${ }^{e}$ siècle ${ }^{91}$ : avant leur mise bas, les petits broutent l'herbe en sortant leur tête du ventre de leur mère, puis $\mathrm{y}$ retournent une fois rassasiés. Après la naissance, les girafons s'enfuient immédiatement, car la langue de leur mère leur arracherait la peau en les léchant ! Ainsi, les petits se tiennent éloignés pendant quelques jours. Un témoignage occidental reprend cette légende arabe, avec quelques variantes. Félix Fabri, visitant la ménagerie du Caire en 1483, résume ainsi la légende rapportée par Ibn Bahtī̌̌ū :

« Lorsqu'elle conçoit, le petit ne grossit pas dans ses flancs ; elle ne gonfle pas comme les autres animaux en grossesse, mais le fotus se trouve suspendu à la matrice et grandit au dehors, au point que le petit, ainsi suspendu, lape sa nourriture à terre et mange des herbes. La mère, à l'encontre de la nature de presque tous les animaux, a son petit en horreur, mais elle ne peut lui faire de tort, bien qu'elle supporte beaucoup de tourments tout le temps qu'elle le porte. Lorsque le moment de la parturition est venu, [le petit] tombe de lui-même comme le fruit de l'arbre, lorsqu'il est parvenu à une maturité suffisante. Dès qu'il est tombé à terre, il prend aussitôt la fuite, car la mère, dès qu'elle se sent libérée, se retourne et cherche à le tuer. » ${ }^{92}$

Alors que cette légende semble inconnue en Occident, étant notamment absente des encyclopédies médiévales latines, le fait qu'elle ait été rapportée à un voyageur occidental démontre qu'elle était bien connue et diffusée en terre d'islam.

Cette histoire trouve peut-être son origine dans l'observation de la naissance des girafons: la girafe met bas debout, et le nouveau né fait donc une chute assez brutale de près de deux mètres. Rapidement, la mère le débarrasse de la poche placentaire en le léchant. La naissance pouvant être assez longue, jusqu'à plusieurs heures, il n'est pas rare d'observer les pattes et la tête sortant du ventre de la mère, pouvant donner l'impression d'une « grossesse externe ${ }^{93}$ (voir figure 3). La vision d'une girafe mangeant et arrachant le placenta avec sa longue langue noire, a dû certainement impressionner les témoins d'une telle scène, sans doute vue dans une ménagerie plutôt que dans la nature. La naissance d'un girafon à la citadelle du Caire au XIII ${ }^{\mathrm{e}}$ siècle, déjà évoquée, confirmerait cette idée.

88 Al-Mas 'ū $\mathrm{u}$, Les prairies d'or, trad. PELLAT, p. 322.

89 Al-Mas' ū $\overline{\mathrm{i}}$, Les prairies d'or, trad. PELLAT, p. 322.

90 New York, Pierpont Morgan Library, M 500, f. 16.

91 HILLENBRAND 1991, p. 155-156. Le manuscrit, produit à Maragha, au nord-est de l'Iran, est une traduction en persan d'un original arabe.

92 Félix Fabri, Voyage en Égypte, trad. MASson, II, p. 421.

93 DAGG et FOSTER 1976, p. 134. 
D'autre part, il n'est pas rare que des girafons soient blessés lors de leur chute et qu'ainsi assommés, leur mère essaie de les « réveiller » en leur donnant des coups de patte, ce qui a pu passer pour de la violence envers son petit ${ }^{94}$. Il peut arriver que la mère rejette violemment son petit. En février 2012, le sort d'un girafon né dans un zoo en Belgique, le parc de Bellewaerde à Ypres, avait ému le public : grièvement blessé par sa mère après la mise bas, et souffrant d'une fracture ouverte à la patte avant droite, il dut être euthanasié ${ }^{95}$.

Ces histoires autour de la naissance des girafons peuvent être rapprochées de légendes relatives au rhinocéros. Selon al-Damīrī, qui nomme le rhinocéros al-sinād, le petit sortirait sa tête de temps en temps pour brouter durant la grossesse; à la naissance, le jeune rhinocéros s'enfuit car la langue de la mère est trop rugueuse et peut lui arracher les chairs par léchage quand elle parvient à le rattraper ${ }^{96}$. Al-Ǧahīz dit que la gestation dure sept ans, attribue cette légende aux Hindous, et ne reprend pas l'anecdote de la langue « arracheuse de chair $"{ }^{97}$. Al-Mas'ū $\bar{d} \overline{1}$ critique Al-Ğahīị pour avoir repris ces légendes, et dit s'être renseigné sur le sujet auprès d'habitants de l'Inde et de négociants d'Oman et de Siraf fréquentant ces régions : tous lui ont affirmé que le rhinocéros porte et met bas comme la vache et le buffle ${ }^{98}$. Al-Zuhrī mentionne la parturition du rhinocéros (al-karkaddān) et attribue cette anecdote au géographe andalou al-'Ūdrī (m. 1086) : " al-'Ū $\underline{d} r \overline{1}$ prétend que, du sein de sa mère, cet animal sort sa tête par la vulve pour brouter l'herbe puis rentre et cela jusqu'à sa naissance. ${ }^{99}$ » Un autre auteur d'origine andalouse, Abū Ḥāmid al-Ġarnātị (m. 1170), parle, à propos du rhinocéros (al-karkaddān), d'une gestation de quatre ans et précise que le petit, au bout d'un an de gestation, se nourrit en sortant la tête du ventre pour paître au milieu des arbres à sa portée ; à la naissance il s'enfuit pour échapper à sa mère, dont la langue possède un grand piquant qui lui arracherait la peau si elle léchait. Al-Ġarnāți ajoute même que les rois de Chine livrent un prisonnier au rhinocéros « pour que celui-ci le lèche et que les os du supplicié ne conservent plus aucune chair. » ${ }^{100}$

Il n'y a pourtant que peu de rapport entre rhinocéros et girafe et il est difficile d'expliquer pourquoi cette légende est partagé par ces deux animaux ; à notre connaissance, un seul auteur rapproche les deux espèces, Ibn Qutayba, qui traduit le mot persan désignant la girafe uštūr-gaw-palank en un mélange de chameau et de rhinocéros ${ }^{101}$.

\footnotetext{
94 DAGG et FOSTER 1976, p. 135-137.

95 Voir site de la RTBF (http://www.rtbf.be), « Un girafon ne survit pas aux attaques de sa mère à Bellewaerde », 4 février 2012. [En ligne] http://goo.gl/BhroH

96 Al-Damīrī, Hayāt al-ḥayawān, trad. JAYAKAR, II, p. 81-82.

97 Al-Ǧāḥiz, Kitāb al-ḥayawān, VII, 123-124, trad. SoUAMI, p. 337.

98 Al-Mas'ūì̄i, Les praires d'or, éd. BARBIER DE MEYNARD et PAVET DE COURTEILLE, I, p. 387-388.

99 Al-Zuhrī, Kitāb al-ğa rāfiyya, p. 35 et texte arabe § 25 p. 295.

100 Abū Ḥāmid al-Ġarnāțī, Tuhfat al-albāb, éd. et trad. FERRAND, p. 109-110 (texte arabe) et 267 (traduction).

101 Ibn Qutayba, 'Uyūn al-aḩbār, éd. Qamīša, II, 83, cité par KRUK 2008, p. 581.
} 


\section{La longue postérité de l'hybridité de la girafe}

L'observation attentive de la nature, nous l'avons vu, n'exclut pas, bien au contraire, la création de légendes et leur croyance sur le long terme. Alors que l'origine hybride de la girafe a été très tôt dénoncée, elle va portant être reprise par de nombreux auteurs, et ce jusqu'au XIX ${ }^{e}$ siècle : un savant marocain, Muḥammad al-Șaffār, visitant le jardin des Plantes à Paris en 1846, décrit la girafe qu'il observe au zoo, mais en y ajoutant des références à son hybridité supposée, même s'il la remet en question. Cette anecdote témoigne du succès sur la longue durée des livres des merveilles médiévaux comme, par exemple, le 'Ağā'ib al-mahlūqāt d'al-Qazwīnī, dont al-Ṣaffār tire peut-être la légende de l'origine hybride de la girafe ${ }^{102}$.

Bien loin du scepticisme et du rationalisme d'al-Ǧāhị et d'al-Mas'ūdī, de nombreux auteurs vont reprendre cette histoire sans la mettre en doute. Le premier est Ibn Qutayba (m. 889-890), qui reprend l'hybridation «au carré » décrite par al-Ǧāhiz - croisements successifs entre la chamelle, la vache sauvage (baqara wahšsiyya) et l'hyène mâle (dib'ān) - et la justifie par l'étymologie du mot zaräfa, qui signifie " groupe ». Selon Ibn Qutayba, la girafe porte le nom de zarāfa car elle forme en une seule espèce tout un groupe d'animaux ${ }^{103}$. Ibn Hallikān justifie également le nom de la girafe, dont il donne le sens de "collection ", car cette espèce est le produit de plusieurs animaux ${ }^{104}$. Cette explication est également avancée par Ibn al-Faqīh al-Hamadānīi ${ }^{105}$ et par al-Wațwāț, qui pourtant mettent en doute la véracité de cette légende. Al-Wațwāṭ justifie alors le sens du mot zarāfa par sa ressemblance avec d'autres animaux: cou de chameau, cornes de gazelle, peau de panthère, dents de vache, tête de cerf, justifiant ainsi l'idée de "groupe » ou d' "assemblée » présente dans l'étymologie ${ }^{106}$.

D'autres auteurs arabes ne reprennent pas cette hybridation au bout de deux générations et se contentent d'une hybridité «simple » entre un camélidé et un animal tacheté (panthère ou hyène), ou de dire simplement qu'elle est le produit de plusieurs animaux, sans en détailler ni le processus ni les espèces en cause, comme al-Zuhrī ( « On dit qu'elle est née de deux espèces d'animaux » $\left.{ }^{107}\right)$. Al-Qazwīnī (m. après 1340) pense que la girafe est le produit d'une vache sauvage et d'un chameau ${ }^{108}$.

Le reprise continuelle de la légende de l'origine hybride de la girafe, sans toujours beaucoup de distance critique, est le fruit des compilations successives mais aussi d'un goût du merveilleux, notamment dans les traités de géographie ou les livres des merveilles, comme celui d'al-Qazwīnī. La persistance de cette légende, sur la longue durée, jusqu'au

102 KRUK 2008, p. 570 et 580.

103 Al-Qutayba, 'Uyūn al-ahbār, II, 83, cité dans The Natural History Section from a 9th Century Book of Useful Knowledge, éd BODENHEIMER et KOPF, p. 43-44.

104 KRUK 2008, p. 581.

105 Ibn Al-Faqīh al-Hamad̄ān̄i, Abrégé du Livre des pays, trad. MASSÉ, p. 94.

106 Al-Wațwāt, Manāhiğ al-fikar wa-mabāhiğ al-'ibar, éd. SZEGIN, p. 82, cité par KRUK 2008, p. 587.

107 Al-Zuhrī, Kitāb al-ğa rāfiyya, éd. HADJ-SADOK, § 328, p. 185.

108 Hamd Allāh al-Mustawfī al-Qazwīnī, The zoological section of the Nuzhatu-L-Qulūb, éd. STEPHENSON, p. 16. 
XVIII ${ }^{\mathrm{e}}$ siècle, va avoir une influence importante sur le statut alimentaire de la viande de girafe, dans le cadre des lois islamiques sur la consommation de chair animale.

\section{Peut-on manger de la girafe ?}

Son statut d'animal bien connu ${ }^{109}$, à la fois par sa présence dans les ménageries arabes et par les nombreuses descriptions dans les encyclopédies (figures 2 et 4), a été logiquement interrogé par les juristes : la consommation de viande de girafe est-elle licite selon l'islam? Pour certains, sa viande est illicite car venant d'un animal hybride, issu d'une espèce pure et d'une autre impure : l'âne (illicite) et le chameau (licite) ${ }^{110} \mathrm{ou}$, comme nous l'avons vu, entre l'hyène (illicite en général mais qui a un statut ambigu ${ }^{111}$ ), la chamelle et la vache (licites).

D'autres juristes la considèrent comme licite car c'est une bête à cornes assimilable à un bovidé ${ }^{112}$, enfin un troisième groupe la considère comme une espèce propre, suivant ainsi al-Ǧāhì, al-Mas ū ūī, ou al-Damīrī. De fait, les auteurs arabes l'ont souvent comparée aux camélidés ou aux bovidés : Ibn Qudāma (m. 1223) la rapproche du dromadaire ${ }^{113}$; alBašarī (XVIII ${ }^{\mathrm{e}}$ s.), des bovidés et des bêtes à cornes en général ${ }^{114}$; al-Nuwayrī classe la girafe parmi les herbivores sauvages et les antilopes, avec l'éléphant, le rhinocéros, l'addax, le cerf, l'onagre, le chamois, la gazelle, le singe et l'autruche ${ }^{115}$; al-Damīīi la rapproche du bœuf et du chameau ${ }^{116}$. La plupart des auteurs s'accordent sur son statut de ruminant ${ }^{117}$, produisant des crottes comme un chameau ${ }^{118}$. Al-Damīīi précise même qu'elle fait des petites crottes rondes ${ }^{119}$, ce qui correspond bien aux déjections des girafes. Il ajoute qu'elle est facile à apprivoiser. Al-Mas ūìī précise que dans cette espèce, comme parmi les éléphants, il y a des individus sauvages et d'autres domestiqués ${ }^{120}$. Cette classification est

109 Al-Qazwīnī et al-Damīrī affirment que cet animal est bien connu ; les géographes, comme al-Idrisī, qui la citent parmi la faune des pays africains, ne prennent pas toujours soin de la décrire, comme si elle était connue de façon évidente par les lecteurs.

110 Ihwān al-Ṣafā' (Xe s.), Rasā'ìl, II, 218, cité par BENKHEIRA 2000, p. 95 ; The Case of the Animals versus Man before the King of the Jinn [Ihwān al-Ṣafầ, Épitre 22, chap. 5], trad. L. E. GOODMAN et R. MCGREGOR, 2009, p. 120.

111 BENKHEIRA 2000, p. 95 et 111-112, note 2.

112 BENKHEIRA 2000, p. 95. Voir par exemple al-Qazwīnī qui assure que sa chair peut être mangée car la girafe est le produit du chameau et de la vache des montagnes (The zoological section of the Nuzhatu, éd. STEPHENSON, p. 16).

Ibn Qudāma, Al-Muġnī, XIII, 324, nº 1738, cité par BENKHEIRA 2000, p. 95.

114 Al-Bašarī, Maknūn-azā in, III, 11, cité par BENKHEIRA 2000, p. 95.

115 BENKHEIRA 2005, p. 34.

116 Al-Damīīi, Hayāt al-hayawān, trad. JAYAKAR, II, p. 8-11.

117 Par exemple al-Qazwīn̄i, qui la classe dans les ruminants (an'ām) avec les camélidés, bovidés, ovicapridés, antilopes et cervidés). Voir BENKHEIRA (2005) sur les classifications animales dans la zoologie arabe dans (p. 1942, sp. p. 29) pour les classements d'al-Qazwīnī.

118 Al-Dimašqī, éd. MeHren, II, p. 215 ; Planhol 2004, p. 569.

119 Al-Damīrī, Hayāt al-ḩayawān, trad. JAYAKAR, II, p. 8-11. Le mot utilisé est ba'ara qui, selon le dictionnaire de Kazimirski, signifie « crotter », plus particulièrement en parlant des crottes orbiculaires rondes des bêtes à sabots.

Al-Mas' ūdī, Les praires d'or, éd. PELLAT, § 846, p. 322. 
confirmée au XVI ${ }^{\mathrm{e}}$ siècle par Prosper Alpin, qui affirme que les Égyptiens « ont raison de ne pas classer la girafe parmi les animaux sauvages $»{ }^{121}$. En l'absence de témoignages sur la domestication des girafes à des fins d'élevage, les remarques d'al-Mas'ūdī et d'al-Damīrī semblent se référer aux spécimens captifs des ménageries princières qui ont, la plupart du temps, été capturés très jeunes, donc domestiqués et apprivoisés tôt par l'homme.

Al-Damīrī s'interroge sur le statut alimentaire de la girafe, comme il le fait pour tous les animaux de son encyclopédie ${ }^{122}$. Reprenant la thèse d'al-Ǧăhiz, il réfute l'hybridité supposée de la girafe, seul argument proposé par les juristes pour déclarer illicite sa viande. La girafe n'est pas non plus un prédateur carnivore, et elle ressemble aux animaux licites comme les bovidés ou les camélidés. Le long passage d'al-Damīrī sur le statut alimentaire de la girafe nous renseigne sur les débats entre juristes. Al-Damīrī cite de nombreux auteurs qui argumentent pour l'une ou l'autre position, pureté ou impureté de la viande de la girafe ${ }^{123}$. Aucun des auteurs cités par al-Damīrī - qui discute surtout du statut hybride - ne signale que la girafe est une espèce propre, un herbivore ruminant à cornes, ce qui rendrait inutile tout débat, car ces éléments désignent sans ambiguïté des animaux propres à la consommation. Au contraire, la suspicion d'hybridité avec l'hyène, le tigre ou la panthère, ferait d'elle un carnassier portant des canines, type d'animal dont la consommation est interdite. Al-Damīî̄ cite à ce propos Ibn-Abī al-Dam al-Hamawī (m. 1244), auteur de commentaires sur divers traités juridiques ${ }^{124}$ : si la girafe était le fruit d'un animal carnassier obtenant sa nourriture par ses canines, elle serait impure. Mais il n'a jamais entendu dire en Égypte que la girafe était un prédateur, et ajoute que tous ceux qui en ont fait l'hypothèse avant lui n'avaient certainement jamais vu cet animal ${ }^{125}$.

Rien n'interdisant nommément la girafe dans les écrits coraniques, la girafe fait partie de ces animaux où il n'y a pas de déclaration distincte entre licéité et illicéité. Al-Damīrī déclare à ce propos que cette espèce entre dans la catégorie des animaux où il n'y a pas de statut clairement défini, et que l'on peut alors revenir à la permission originelle : ce qui n'est pas interdit nommément est déclaré légal ${ }^{126}$. Si la consommation de viande de girafe devait être très rare au Maghreb et au Machrek, il en était tout autrement en Afrique noire. La chasse à la girafe semble avoir été courante chez les tribus islamisées. L'animal était tué

121 Prosper Alpin, Histoire naturelle de l'Égypte (1581-1584), II, éd. SAUNERON et DE FENOYL, p. 236-237.

122 Al-Damīīī, Hayāt al-hayawān, trad. JAYAKAR, II, p. 8-11.

123 Viande impure : al-Nawawī; l'auteur du al-Tanbịh ; Abū al-Ḩattāb. Viande pure : al-Ḥamawī. BENKHEIRA (2000, p. 95 et 111-112) cite, outre al-Nawawī, dans le camp de « l'impureté » : al-Bağawī (m. avant 1122), Ibn Hağar al-Haytamī (m. 1567), Šams al-Dīn al-Ramlī (m. 1595) ; dans le camp de la " pureté », Ibn Qudāma (m. 1223) et al-Bašarī (XVIII $\mathrm{e}$.$) .$ ROSENTHAL 1986.

125 Al-Damīīi, Hayāt al-hayawān, trad. JAYAKAR, II, p. 10.

126 Al-Damīīi, Hayāt al-hayawān, trad. JAYAKAR, II, p. 11. 
surtout pour le commerce de sa peau ${ }^{127}$ de son cuir ${ }^{128}$ et de sa queue ${ }^{129}$, mais également pour sa viande. Al-Qazwīnī raconte que les habitants musulmans ou idolâtres de la région de Takrūr (ville située sur le fleuve Sénégal, à la frontière de l'actuel Sénégal et de la Mauritanie) chassent la girafe dans ce pays, où elle abonde, et qu'ils l'égorgent exactement comme un bœuf ${ }^{130}$. Selon les récits de voyageurs occidentaux au XIX ${ }^{\mathrm{e}}$ siècle, les Arabes ont chassé depuis des siècles la girafe à dos de chameau ou à cheval : ne disait-on pas, chez les Arabes, d'un cheval rapide qu'il était capable de dépasser une girafe ${ }^{131}$ ? Jean Thenaud, qui voyage en Égypte en 1512, raconte qu'un riche juif du Caire, "grand ami du Sultan », fit tuer une girafe "pour sumptuosité » pour les noces d'une de ses filles ${ }^{132}$. Cette anecdote montre que pour un juif (qui partage avec les musulmans des interdits alimentaires assez semblables), la girafe pouvait être consommée à l'occasion et même constituer un plat de fête, même loin des régions où elle pouvait constituer un gibier naturel.

Al-Damīrī signale que la viande de girafe est fruste et grossière et provoque la bile noire (atrabile, qui corrompt l'humeur mélancolique) ${ }^{133}$. C'est peut-être pour lui une façon de clore la polémique sur la pureté : cette viande n'est pas très agréable au goût et mauvaise pour la santé. On retrouve ici les anciennes croyances sur la viande d'animaux sauvages, réputée sèche, froide et atrabilaire, comme le mentionne, par exemple, Ibn Halṣūn au XIII ${ }^{\mathrm{e}}$ siècle ${ }^{134}$.

\section{Conclusion}

L'intérêt que les juristes musulmans ont porté à la question de la girafe et à son origine montre que son cas était toujours débattu et son statut d'hybride demeuré incertain jusqu'à l'époque ottomane. On ne peut qu'être frappé par la persistance d'une telle «erreur » sur la longue durée, malgré une bonne connaissance de l'animal et son observation fréquente en captivité, malgré l'autorité d'al-Ǧāhīz et d'al-Mas'ūdī qui ont très tôt démenti cette hybridité supposée. La zoologie médiévale, tant en Orient qu'en Occident, présente souvent un savant mélange d'influences antiques (dont la reprise de mythes et de légendes) et de savoirs vernaculaires contemporains. Dans le cas de la girafe,

127 LOMBARD 1969, p. 580.

128 KRUK 2008, p. 571, qui cite Yāqūt (Mu’ğam al-buldān, II, 100), mentionne des chaussures faites en Perse à partir de peaux de girafes.

129 Niccolo de' Conti ( $\mathrm{XV}^{\mathrm{e}} \mathrm{s}$.) dans son récit de voyage, rapporté par Le Pogge, raconte que les longs poils de girafes (sans doute ceux de leur queue) étaient portés en Éthiopie comme parure au bras de femmes (Poggio Bracciolini, De l'Inde. Les voyages en Asie de Niccolò de' Conti. De Varietate Fortunæ, Livre IV, éd. GUÉRET-LAFERTÉ, p. 176-177).

130 CUOQ 1985, p. 200 ; KRUK 2008, p. 571.

131 DAGG et FOSTER 1976, p. 8-9.

132 Jean Thenaud, Voyage d'outremer, éd. SCHEFER, p. 48.

133 Al-Damīīi, Hayāt al-hayawān, trad. JAYAKAR, II, p. 11.

134 Ibn Hुalșūn, Kitāb al-ag̉diya, 5e partie, 4, § 41, éd. GIGANDET, p. 110 (trad.) et 85 (texte arabe, pagination arabe). Ibn Halșūn ne mentionne pas ici la girafe mais les espèces suivantes: al-waiil (bouquetin), al-ayyal (cerf), alǵazāl (gazelle). 
il s'agit de l'appropriation d'une croyance grecque, mentionnée dans de très rares œuvres, dont celle de Timothée de Gaza, dont nous avons montré qu'elle avait pu être à l'origine de l'hypothèse de l'hybridité de la girafe chez les savants arabes. La permanence, au fil des siècles, des débats à propos de cette hybridité, malgré la contradiction avec les savoirs du temps, par le gré des compilations successives des encyclopédies et des traités de droit, a ainsi formé une croyance communément reprise jusqu'au XIX siècle.

Nous avons vu comment l'observation de naissances de girafes en captivité avait pu, d'une part, infirmer la théorie de l'origine hybride de cet animal et, d'autre part, être à l'origine d'autres légendes sur la gestation et la mise bas des girafons. L'observation de la nature, dans le cas de la girafe, peut à la fois fournir des arguments rationnels sur l'origine de l'animal, tout en permettant l'invention de nouvelles fictions. La description de la girafe, à l'aspect spectaculaire et aux formes si étonnantes a pu fournir des arguments aux tenants de l'hybridité et à leurs opposants ; la description médiévale, sous forme de puzzle zoologique, a pu renforcer l'idée de mélange et d'assemblage, présente dans la racine arabe zarāfa ; l'observation directe a pu au contraire permettre à d'autres auteurs d'affirmer qu'elle ne ressemble en rien à ses pères et mères supposés (chameau, hyène ou panthère) et confirmer que la girafe forme une espèce propre.

L'observation régulière de la naissance de girafons en captivité n'a que très rarement fourni des arguments contre l'origine hybride de la girafe: là encore le goût de la merveille et de la compilation encyclopédique prend la plupart du temps l'avantage sur l'observation de la nature. Il est d'ailleurs très frappant de remarquer que la deuxième légende relative à la naissance de la girafe, mettant en scène une gestation difficile, débouchant sur une naissance où la mère met en danger la vie de son petit, n'est jamais mise en relation avec l'histoire plus courante de l'origine hybride de cet animal. Ces deux légendes semblent d'ailleurs avoir des origines différentes voire opposées, philologique pour l'une, vernaculaire et zoologique pour l'autre. De fait, la naissance des girafons, à la façon habituelle des mammifères, examinée dans une ménagerie ou relatée à travers une histoire mélangeant observation zoologique et conte surnaturel, n'a pas affaibli la légende de l'hybridité sur la longue durée.

Un dernier point vient renforcer cette longue croyance en l'origine hybride des girafes. Al-Mas ūdì explique qu'il y a, comme chez les éléphants, des girafes sauvages et d'autres domestiques ${ }^{135}$. Dans l'épître 22 des Ihwwān al-Ṣafầ, un ğinn conteste au porc son appartenance au bétail domestique, critiquant sa sauvagerie : c'est un prédateur portant des défenses et mangeant de la chair. Un second ğinn affirme au contraire que c'est une bête herbivore portant des sabots. Cette dispute se résout par l'affirmation d'un troisième ğinn qui définit le porc comme étant le produit d'un croisement entre bête sauvage et bétail, tout comme l'éléphant et la girafe ${ }^{136}$. Ces trois animaux sont à la fois des espèces domestiques et sauvages : vivant entre deux mondes, celui de l'homme et celui de la nature,

135 Al-Mas 'ūdī, Les prairies d'or, trad. PELLAT, p. 322.

136 The Case of the Animals versus Man before the King of the Jinn [Ihwwān al-Ṣafā', Épitre 22, chap. 5], trad. L. E. GoodMAN et R. MC GREGOR, 2009, p. 120. 
ils semblent demeurer dans un entre-deux à l'origine indécise. Il était alors tentant pour certains savants arabes, comme les Ihwwān al-Ṣafā', d'expliquer cette indécision par une origine hybride, entre domestique et sauvage, la girafe pouvant provenir du croisement d'un âne, d'un chameau ou d'un bœuf et d'une hyène ou d'une panthère.

Dans l'étude de l'histoire naturelle médiévale, il faut le plus possible tenter de confronter philologie, transmission des textes et reprise de légendes anciennes, en tenant compte de la place « réelle » de l'animal, observable directement, en captivité ou dans son milieu naturel. Le traitement de l'animal dans les textes zoologiques anciens n'est pas seulement " philologique », il est aussi le reflet des relations complexes entre les compilations, parfois serviles, des autorités antiques ou médiévales, la répétition de croyances et de légendes, et l'observation directe de la nature. Les débats autour de l'origine et la naissance des girafes nous en ont donné des exemples frappants.

\section{Bibliographie}

\section{Sources}

Abū Ḥāmid al-Ġarnāțī, « Le Tuhfat al-albāb de Abū Ḥāmid al-Andalusī al-Ġarnāṭ̂̄ », éd. Gabriel FeRRAND, Journal asiatique 207/1-2, 1925, p.1-148 ( $\left.\mathrm{n}^{\circ} 1\right)$; 193-304 ( $\left.\mathrm{n}^{\circ} 2\right)$. [En ligne] http://gallica.bnf.fr/ ark:/12148/bpt6k93307s

Alpin Prosper, Histoire naturelle de l'Égypte (1581-1584), éd. R. de FENOYL et S. SAUNERON, Le Caire, IFAO, 1979 (Collection des voyageurs occidentaux en Égypte, 20).

Aristote, Generation of animals. The Arabic translation commonly ascribed to Yahya ibn al-Bitriq, éd.Jan BRUGMAN, Hendrik Joan DRossaART Lulofs, Leiden, E.J. Brill, 1972 (Publication of the De Goeje Fund, 23).

Aristote, Histoire des animaux, éd. Pierre LouIs, Paris, Les Belles Lettres, 1969 (Collection des universités de France).

Aristote, De la génération des animaux, éd. Pierre LouIs, Paris, Les Belles Lettres, 1961 (Collection des universités de France).

al-Bakrī, Description de l'Afrique septentrionale, éd. W. Mac Guckin de SLANE, Paris, Imprimerie impériale, 1913. [En ligne] http://gallica.bnf.fr/ark:/12148/bpt6k104409x

The Case of the Animals versus Man Before the King of the Jinn. A translation from the Epistles of the Brethren of Purity, trad. Lenn E. GOODMAN et Richard MAC GREGOR, Oxford, Oxford University Press, 2009 (Epistles of the Brethren of Purity).

al-Damīrī, Muhammad ibn Mūsā, Ad-Damīìis Hayāt al-ḥayawān (a zoological lexicon), traduit par A. S. G. JAYAKAR, London, Luzac, 1906.

al-Dimašqī, Šams al-Dīn Muhammad b. Ibrāhīm, Manuel de la cosmographie du Moyen Âge, éd. A.-F. MEHREN, Copenhague-Paris-Leipzig, Reitzel-Leroux-Brockhaus, 1874. [En ligne] http://www.archive.org/ details/manueldelacosmo00dimagoog

Diodore de Sicile, Naissance des Dieux et des Hommes. Bibliothèque historique, Livres I et II, éd. M. CASEVITZ, Paris, Les Belles Lettres, 1991 (La Roue à livres). 
Fabri Félix, Voyage en Égypte, éd. J. MASSON, Le Caire, IFAO, 1974 (Collection des voyageurs occidentaux en Égypte, 14).

Frescobaldi Lionardo di Niccolò, Gucci Georgio et Sigoli Simone, Viaggi in Terra Santa, di Lionardo Frescobaldi e d'altri del secolo XIV, éd. Carlo GARGIOLLI, Firenze, G. Barbera, 1862.

al-Ǧāhiz, Le cadi et la mouche: anthologie du "Livre des animaux», traduit par Lakhdar SoUAMI, Paris, Sindbad, 1988 (Bibliothèque arabe. Collection Les Classiques).

al-Ǧāhiz, « Le Kitāb al-Tarbî wa-l-tadwīr d'al-Ǧāhị : Traduction française, II », éd. Maurice ADAD, Arabica 14/1, 1967, p. 32-59. [En ligne] http://www.jstor.org/stable/4055903, DOI : 10.2307/4055903

al-Ǧāhiz, Kitāb al-Hayawān, éd. 'Abd al-Salām Muhammad HĀRŪN, Le Caire, Matb'at Mustafā-l-Bābī-lHalabī, 1938-1945.

Héliodore, Éthiopiques, éd. Robert Mantle RATTENBURY et Thomas Wallace LUMB, traduit par Jean MAILLON, Paris, 1943 (Collection des universités de France).

Ibn al-Faqīh al-Hamadān̄ī, Abrégé du Livre des pays, traduit par Henri MAssÉ, Damas, Institut français de Damas, 1973 (PIFD, 97). [En ligne] http://books.openedition.org/ifpo/6217

Ibn al-Faqīh al-Hamad̄ānī, Compendium Libri Kitāb al-Buldān, éd. M. J. de GoEJE, Leiden, Brill, 1885.

Ibn Hualṣūn, Kitāb al-Ag̀diya, éd. Suzanne GIGANDET, Damas, IFEAD, 1996 (PIFD, 158).

Ibn Quttayba, The Natural History Section from a 9th Century Book of Useful Knowledge. The 'Uyūn Al-Ahbār of Ibn Qutayba, éd. Friedrich Simon BODENHEIMER et Lothar KoPF, Paris-Leyde, 1972 (Collection de travaux de l'Académie internationale d'histoire des sciences, 10).

Ibn Quțayba, 'Uyūn al-ahbār, éd. M. M. QAMĪšA, Beyrouth, 1986.

Kušāğim, Kitāb al-mașāyid wa'l-mațāìid, éd. Muhammad TALAS, Bagdad, 1954.

Léon l'Africain, Description de l'Afrique, éd. Th. MONOD, H. LHOTE et R. MAUNY, traduit par A. ÉPAULARD, Paris, Maisonneuve, 1956.

Léon l'Africain, De l'Afrique, contenant la description de ce pays..., éd. J. Temporal, Paris, 1556 [En ligne] http://gallica.bnf.fr/ark:/12148/bpt6k1044206.

al-Maqrīzī, Histoire des sultans mamlouks de l'Égypte, éd. Étienne QuATREMÈRE, Paris, Duprat, 1836 (Publications, Oriental Translation Fund, 47). [En ligne] http://www.jstor.org/stable/4056449

al-Maqrīzī, Description historique et topographique de l'Égypte (Livre des admonitions et de l'observation pour l'histoire des quartiers et des monuments) $3^{e}-4^{e}$ parties, éd. Paul CASANOVA, Le Caire, IFAO, 1906-1910 (Mémoires publiés par les membres de l'IFAO du Caire, 3-4), 3. [En ligne] http://gallica.bnf.fr/ ark:/12148/bpt6k5806744c

Al-Mansur's Book on Hunting, éd. Terrence CLARK et Muawiya DERHALLI, Warminster, Aris \& Phillips, 2001.

al-Mas'ū ūi, 'Alī ibn al-Ḥusayn, Les prairies d'or (Murūğ al-dِahab wa ma'ādin al-ğawhar), trad. Charles PeLLAT, Paris, Société asiatique - Imprimerie nationale, 1962 (Collection d'ouvrages orientaux).

al-Mas'ūd̄i, 'Alī ibn al-Husayn, 1861, Les prairies d'or, éd. Charles BARBIER DE MEYNARD et Abel PAVET DE COURTEILLE, Paris, Imprimerie impériale, 1861 (Collection d'ouvrages orientaux).

al-Nuwayrī, Nihāyat al-adab fí funūn al-'arab, Le Caire, 1923-1997.

Ogier d'Anglure, Le saint voyage de Jherusalem du seigneur d'Anglure, éd. François BONNARDOT et Auguste LONGNON, Paris, Firmin Didot, 1878 (Société des anciens textes français). [En ligne] http://gallica. bnf.fr/ark:/12148/bpt6k51241

Oppien, Cynegetica, éd. Alexander William MAIR, Cambridge-Londres, 2002 (Loeb Classical Library, 219).

Pline l'Ancien, Histoire naturelle. Livre VIII, éd. Alfred ERNOUT, Paris, Les Belles Lettres, 2003. 
Poggio Bracciolini, De l'Inde. Les voyages en Asie de Niccolò de' Conti. De Varietate Fortunæ, Livre IV, éd. M. GUÉRET-LAFERTÉ, Turnhout, Brepols, 2004 (Miroir du Moyen Âge).

Poséidonios d'Apamée, Die Fragmente, éd. W. THEILER, Berlin-New York, 1982.

al-Qalqašandī, Subh al-a ‘̌s̄a fî șinā'a al-inšă’, Le Caire, Wizāra al-țaqāfa l-mișriyya, 1913.

al-Qazwīnī, The zoological section of the Nuzhatu-l-Qulūb of Hamdullāh al-Mustaufíal-Qazwīnī,éd.J. STEPHENSON, London, Routledge, 2007 [Facsimile ed] (The Muslim world, 7 ; Royal Asiatic Society classics of Islam, 2).

Scholia et Paraphrases in Nicandrum et Oppianum, éd. Ulco CATS BUSSEMAKER Ulco, Paris, Firmin Didot, 1849. [En ligne] http://gallica.bnf.fr/ark:/12148/bpt6k28230s

Strabon, The Geography of Strabo, éd. Horace Leonard JoNES, London - New York, 1917-1932 (Loeb Classical Library).

Supplementum Aristotelicum. I. Aristophanis Historiae animalium epitome II. Excerptorum Constantini de natura animalium Libri duo Aristophanis Historiae animalium epitom, subjunctis Aeliani Timothei aliorumque eclogis, éd. Spiridon LAMBROS, Berlin, Reimer, 1885 (Commentaria in Aristotelem Graeca). [En ligne] http://www.archive.org/details/supplementumari01arisgoog

Thenaud Jean, Le voyage d'Outremer (Égypte, mont Sinay, Palestine) de Jean Thenaud, etc., éd. Charles SCHEFER et Zakaria PAGANI, Paris, Leroux, 1884 (Recueil de voyages et de documents relatifs à l'histoire de la géographie, depuis le XIII ${ }^{e}$ jusqu'au XVI ${ }^{e}$ siècle, 5). [En ligne] http://gallica2.bnf.fr/ark:/12148/ bpt6k104376w

Timothée de Gaza, Peri zôôn (On animals), traduit par Friedrich Simon BODENHEIMER et Alexander RABINOWITZ, Paris, Académie internationale d'histoire des sciences (Collection de travaux de l'Académie internationale d'histoire des sciences, 3), 1949.

Timothée de Gaza, «Excerpta ex Timothei Gazaei libris de animalibus », éd. Mauritz HAUPT, Hermes 3, 1869, p. 1-30. [En ligne] https://archive.org/details/jstor-4471051

al-Wațwāt, Manāhiğ al-fikar wa-mabāhiǧ al-ibar, éd. Fuat SEZGIN ET M. AMAWI, Frankfurt am Main, Goethe Universität, 1990.

al-Zuhrī, « Kitāb al-ğa'rāfiyya. Mappemonde du calife al-Ma’mūn reproduite par Fazārī (III ${ }^{e}-I X^{e}$ s.) rééditée et commentée par Zuhrī ( $\mathrm{VI}^{\mathrm{e}}-\mathrm{XII}{ }^{\mathrm{e}} \mathrm{s}$.) », éd. Muhammad HADJ-SADOK, Bulletin d'études orientales 21, 1968, p. 1-312. [En ligne] http://www.jstor.org/stable/41603291

\section{Études}

ADAD Maurice 1966, « Le Kitāb al-Tarbī wa-l-tadwīr d'al-Ǧāḥiz : Traduction française, I », Arabica 13/3, p. 268-294. [En ligne] http://www.jstor.org/stable/4055927, DOI : 10.2307/4055927

BENKHEIRA Mohammed Hocine, MAYEUR-JAOUEN Catherine et SUBLET Jacqueline 2005, L'animal en islam, Paris, Les Indes savantes.

BENKHEIRA Mohammed Hocine 2005, « Classer l'animal », in L'animal en islam, p. 19-42.

BENKHEIRA Mohammed Hocine 2000, Islam et interdits alimentaires: juguler l'animalité, Paris, Presses universitaires de France (Pratiques théoriques).

BODSON Liliane 2005, « Naming the Exotic Animals in Ancient Greek and Latin », in Gherardo ORTALLI, Alessandro MINELLI et Glauco SANGA (éd.), Animal names (Actes du colloque international, oct. 2003), Venise, Istituto Veneto di Scienze, Lettere ed Arti, p. 453-482. 
BUQUET Thierry 2013, « Animalia extranea et stupenda ad videndum. Describing and Naming Exotic Beasts in Cairo Sultan's Menagerie ", in Monica A. WALKER VADILLO, Francisco de Asís GARCíA GARCÍA et María Victoria CHICO PICAZA (éd.), Animals and the Otherness in the Middle Ages. Perspectives across disciplines, Oxford, Archeopress (British Archaeological Reports. International Series, 2500), p. 25-34. [En ligne] http://halshs.archives-ouvertes.fr/halshs-00845246

BUQUET Thierry 2012 a, «Les panthères de Timothée de Gaza dans l'encyclopédie zoologique de Constantin VII », Rursus. Poiétique, réception et réécriture des textes antiques 7. [En ligne] http://rursus. revues.org/971, DOI : 10.4000/rursus.971

BUQUET Thierry 2012 b, «La belle captive. La girafe dans les ménageries princières au Moyen Âge », in Corinne BECK et Fabrice GUIZARD (éd.), La bête captive au Moyen Âge et à l'époque moderne, Amiens, Encrage (Encrage université), p. 65-90. [En ligne] http://halshs.archives-ouvertes.fr/ halshs-00664537

BUQUET Thierry 2011, « Le guépard médiéval, ou comment reconnaître un animal sans nom », Reinardus. Yearbook of the International Reynard Society 23, p. 12-47. [En ligne] http://halshs.archives-ouvertes. $\mathrm{fr} /$ halshs-00655131/fr/, DOI : 10.1075/rein.23.02buq

BUQUET Thierry 2008, «La girafe, belle inconnue des bibles médiévales. Camelopardalis: un animal philologique », Anthropozoologica 43/2, p. 47-68. [En ligne] http://halshs.archives-ouvertes.fr/ halshs-00352040/fr/

BUQUET Thierry 2006, «Pourquoi la Bible des Septante a-t-elle traduit le zemer du Deutéronome en kamelopardalis ? Réflexions sur le statut symbolique et alimentaire de la girafe », Anthropozoologica 41/1, p. 7-25. [En ligne] http://halshs.archives-ouvertes.fr/halshs-00089601

CANNUYER Christian 2010, La girafe dans l'Égypte ancienne et le verbe SR. Étude de lexicographie et de symbolique animalière, Bruxelles, Société Belge d’Études Orientales Éditions Illustrata sprl (Acta Orientalia Belgica-Subsidia, 3).

CONTADINI Anna 2003, «A Bestiary Tale : Text and Image of the Unicorn in the Kitāb Na'at al-hayawān (British Library, or. 2784)», Muqarnas 20, p. 17-33. [En ligne] http://www.jstor.org/stable/1523325, DOI : $10.2307 / 1523325$

CUoQ Joseph 1985, Recueil des sources arabes concernant l'Afrique occidentale du VIII au XVI siécle (Bilâd AlSûdân), Paris, CNRS éditions (Sources d'histoire médiévale, 6).

DAGG Anne Innis et FOSTER J. Bristol 1976, The Giraffe: Its Biology, Behavior, and Ecology, Huntington, N.Y., R.E. Krieger Pub. Co.

EISENSTEIN Herbert 1992, Einführung in die arabische Zoographie. Das tierkundliche Wissen in der arabischislamischen Literatur, Berlin, Dietrich Reimer Verlag.

GATIER Pierre-Louis 2005, «Les girafes de Gaza », in Catherine SALIOU (éd.), Gaza dans l'Antiquité tardive: histoire, rhétorique, archéologie: actes du colloque international de Poitiers (6-7 mai 2004), Salerno, Hélios, p. 75-92.

GATIER Pierre-Louis 1996, « Des girafes pour l'empereur », Topoi : Orient-Occident 6/2, p. 903-941.

HILLENBRAND Robert 1991, « Mamlûk and Îlkhânid Bestiaries : Convention and Experiment », Ars Orientalis 20, p. 149-187.

ISKANDAR Albert Z. 1981, « A Doctor's Book on Zoology : al-Marwazi's Taba'i' al-hayawan (Nature of Animals) Re-Assessed », Oriens 27, p. 266-312. [En ligne] http://www.jstor.org/pss/1580569

KoPF Lothar 1956, « The Zoological Chapter of the Kitab al-Imta' wal-Mu'anasa of Abu Hayyan al-Tauhidi (10th Century) », Osiris 12, p. 390-466. [En ligne] http://www.jstor.org/stable/301717 
KRUK Remke 2008, «Zarafa : Encounters with the Giraffe, from Paris to the Medieval Islamic World», in Beatrice GRUENDLER et Michael COOPERSON (éd.), Classical Arabic Humanities in their Own Terms. Festschrift for Wolfahrt Heinrichs on his 65th Birthday, Leiden, Brill, p. 568-592. [En ligne] http://books. google.fr/books?id=n1_qqgNTsX8C

KRUK Remke 2007, « Elusive Giraffes : Ibn Abi L-Ḥawāfir's Badāìi i Al-Akwān and Other Animal Books », in Anna CONTADINI (éd.), Arab Painting: Text and Image in Illustrated Arabic Manuscripts, Leiden-Boston, Brill (Handbook of Oriental Studies. Section 1, The Near and Middle East, 90), p. 49-64. [En ligne] DOI :10.1163/ej.9789004157224.i-272.14

KRUK Remke 2001, « Timotheus of Gaza's On Animals in the Arabic Tradition », Le Museon 114/3-4, p. 355387.

LAUZI Egle 2012, Il destino degli animali. Aspetti delle tradizioni culturali araba e occidentale nel Medio Evo, Florence, Sismel ed. Galluzzo (Micrologus' Library, 44).

LI CAUSI Pietro 2008, Generare in comune. Teorie e rappresentazioni dell'ibrido nel sapere zoologico dei Greci e dei Romani, Palerme, Palumbo (Letteratura classica, 30).

LOMBARD Maurice 1969, «La chasse et les produits de la chasse dans le monde musulman (VIII $-\mathrm{XI}^{\mathrm{e}}$ siècle) », Annales. Histoire, Sciences Sociales 24/3, p. 572-593.

MEINECKE-BERG Victoria 2000, «Das Giraffenbild des fatimidischen Keramikmalers », Damaszener Mitteilungen 11, p. 331-344 + pl. 44-47.

Minniti ColonnA Maria 1977, « Timoteo de Gaza », Vichiana 6, p. 93-102.

MORGAN John Robert 1988, «Two Giraffes Emended », The Classical Quarterly 38/1, p. 267-269. [En ligne] http://www.jstor.org/stable/639235

MuHANNA Elias Ibrahim 2012, Encyclopaedism in the Mamluk Period: The Composition of Shihā b al-Dīn al-Nuwayrī's (d. 1333) Nihāyat al-Arab fì Funūn al-Adab, PhD, Cambridge, Mass., Harvard Univ. (Department of Near Eastern Languages and Civilizations). [En ligne] http://nrs.harvard.edu/urn3:HUL.InstRepos:9366551

PLANHOL Xavier de 2004, Le paysage animal. L'homme et la grande faune : une zoogéographie historique, Paris, Fayard.

ROSENTHAL Franz 1986, «Ibn Abi 'l-Dam », in Encyclopaedia of Islam. $2^{\text {nd }}$ Edition, Leiden-London, Brill-Luzac, III, p. 683.

SUBLET Jacqueline 2005, « La girafe (al-zarâfa) », in L'animal en islam, p. 66-67.

UlLmANN Manfred 1972, Die Natur- und Geheimwissenschaften im Islam, Leiden-Köln, E. J. Brill (Handbuch der Orientalistik. 1, Der Nahe und der Mittlere Osten. Ergänzungsband, 6/2).

VIRÉ François 2005, « Zarāfa », in Encyclopédie de l'Islam, 2e éd., 11 (W-Z), Leiden, Brill, p. 495-496.

VIRÉ François 1993 a, « Na‘ām », in Encyclopédie de l'Islam, 2e éd., 7 (MIF-NAZ), Leiden, Brill, p. 828-831.

VIRÉ François 1993 b, « Namir-Nimr », in Encyclopédie de l'islam, 2 éd., 7 (MIF-NAZ), Leiden, Brill, p. 947950.

WeLLMANN Max 1927, « Timotheos von Gaza », Hermes 62/2, p. 179-204. [En ligne] http://www.jstor.org/ stable/4474040

Zumbo Antonio 1996, «Timoteo di Gaza. De Animalibus », in Byzantina Mediolanensia, V Congresso Nazionale di Studi Bizantini, Milano, 19-22 ottobre 1994. Atti, Messina, Soveria Mannelli Rubbettino (Medioevo Romanzo e Orientale, Colloqui, 3), p. 421-429. 


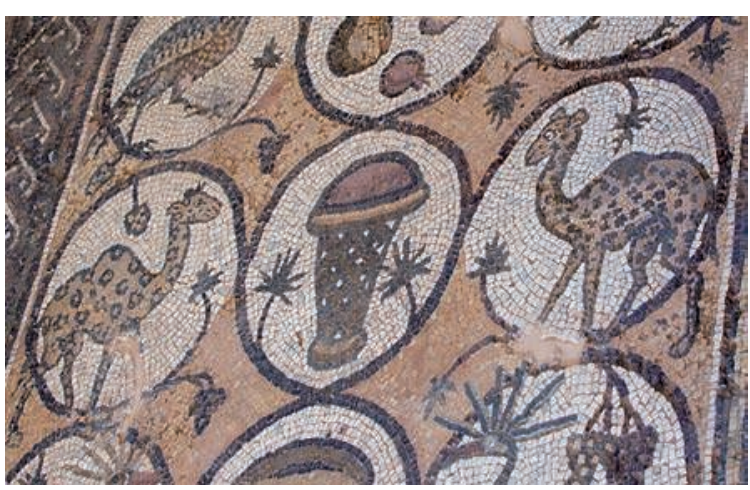

Figure 1 : Deux « caméléopards », mosaïque de l'église Byzantine de Pétra. Non daté (période proto-byzantine?) Photo Thierry Buquet.

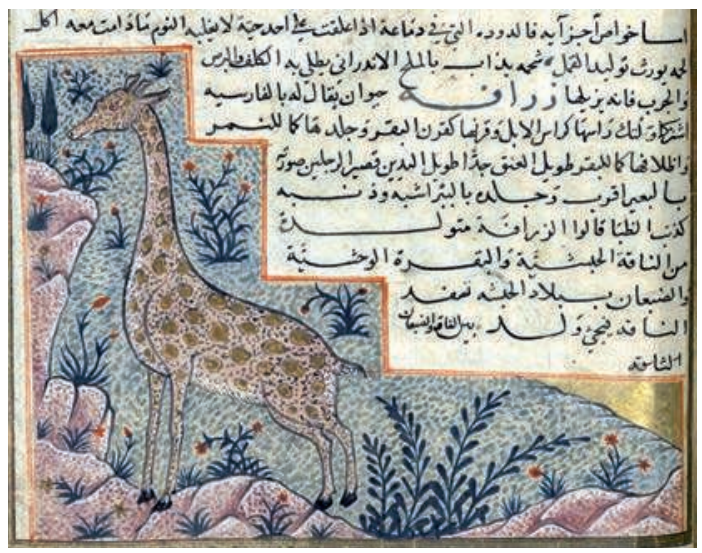

Figure 2: Girafe. al-Qazwīnī, 'Ağầ'ib al-Mahlūqāt (Merveilles de la Création), XIII ${ }^{\mathrm{e}}$ siècle (1274 ?). Bordeaux, Médiathèque, ms. 1130, f. 147.

(c) Banque numérique du savoir d'Aquitaine. Lien image : http://manuscrits-drac.bnsa.aquitaine.fr/ imageZoom.aspx?i=285155\&n=1256

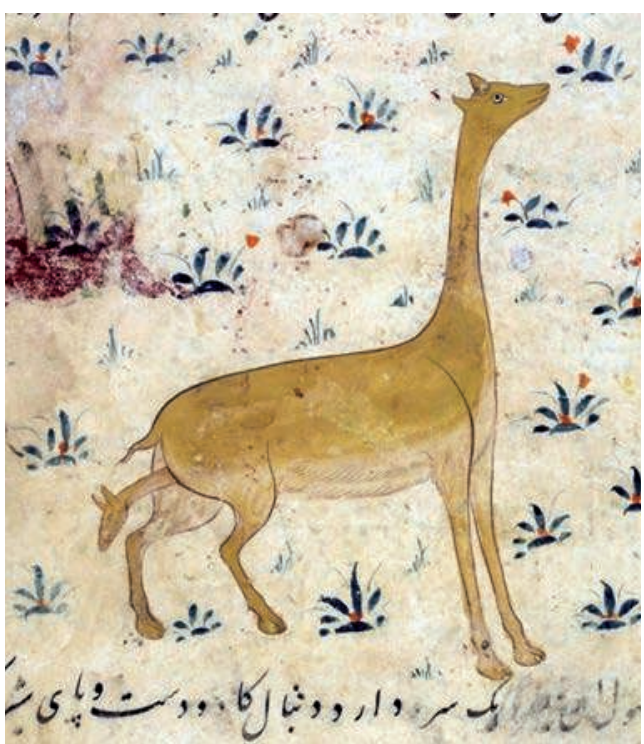

Figure 3 : Girafe mettant bas.

Ṭūsī Salmānī, 'Ağà'ib al-Mahlūqāt, Bagdad, 1388. Paris, BnF, suppl. persan 332, f. 234. (c) BnF Gallica.

Lien image : http://gallica.bnf.fr/ark:/12148/ btv1b8422994d/f481

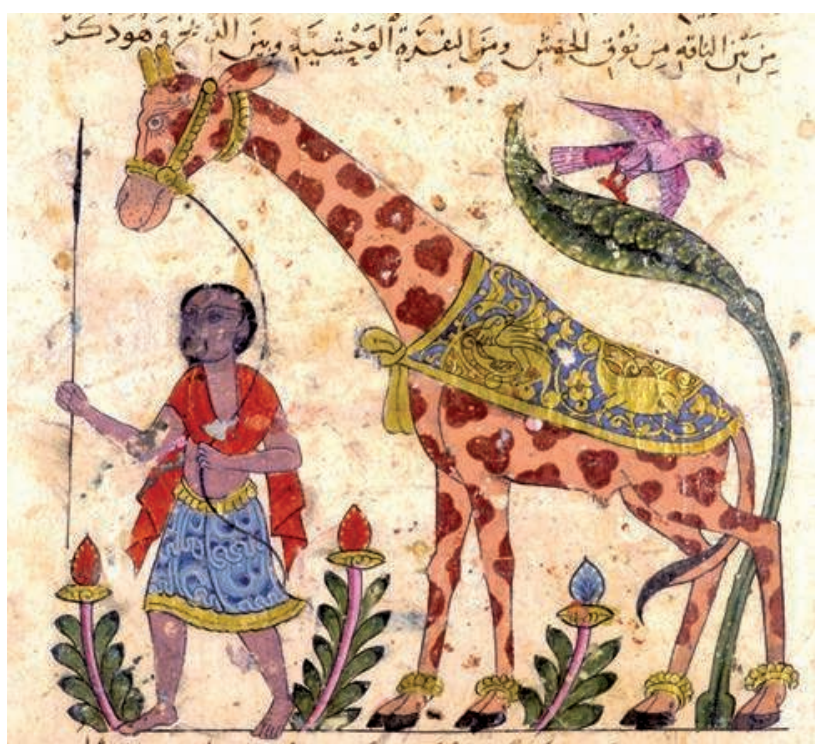

Figure 4 : al-Ǧāhị, Kitāb al-hayawān (Livre des animaux). Syrie, fin du XIV ${ }^{\mathrm{e}}$ siècle.

Milan, Biblioteca Ambrosiana, ms. arab. B 54, f. 36. 
